\title{
A Case of Linear Porokeratosis Superimposed on Disseminated Superficial Actinic Porokeratosis
}

\author{
Rebecca Löhrer ${ }^{\mathrm{a}}$ Aysegül Neumann-Acikel ${ }^{\mathrm{a}}$ \\ Rüdiger Eming ${ }^{b}$ Karin Hartmann ${ }^{\text {a }}$ Heinrich Rasokat ${ }^{a}$ \\ Thomas Krieg $^{a}$ Rudolf Happle ${ }^{b}$ Sabine Eming ${ }^{a}$ \\ a Department of Dermatology, University of Cologne, Cologne, and ${ }^{b}$ Department \\ of Dermatology, University of Marburg, Marburg, Germany
}

\section{Key Words}

Porokeratosis - Linear porokeratosis - Disseminated superficial actinic porokeratosis . Type 2 segmental manifestation

\begin{abstract}
We present a female patient with linear porokeratosis of her right arm since childhood. At the age of 67 years she additionally developed disseminated superficial actinic porokeratosis (DSAP) involving both lower legs. This uncommon coexistence of two different types of porokeratosis fulfils the clinical criteria of a type 2 segmental manifestation of an autosomal dominant skin disorder, being superimposed on the ordinary nonsegmental lesions and reflecting loss of heterozygosity that occurred at an early developmental stage. In DSAP molecular evidence of this concept is so far lacking, but such proof has already been provided in several other autosomal dominant skin disorders. Molecular analysis of cases of type 2 segmental involvement may help elucidate the genetic defect causing DSAP.
\end{abstract}

\section{Case Report}

A 61-year-old woman presented with linear lesions involving her right arm. The patient reported that the skin lesions - known since her childhood - changed during the past weeks. Especially lesions on her upper arm became erosive, increasingly red and pruritic (fig. 1a). Physical examination showed multiple bands consisting of reddish-brown, annular plaques with raised hyperkeratotic ridges and central atrophy. Neither other parts of the integument nor mucosal tissues were affected. Nail dystrophy or any other associated abnormalities were absent. Except for arterial hypertension there were no other diseases. 


\begin{tabular}{c|l|l|l} 
Case Reports $h$ & Case Rep Dermatol 2010;2:130-134 & Published online: August 6, 2010 & $\begin{array}{l}\text { @ 2010 S. Karger AG, Basel } \\
\text { ISSN 1662-6567 } \\
\text { www.karger.com/cde }\end{array}$ \\
\hline
\end{tabular}

To confirm the clinical diagnosis and to exclude malignancy we performed two skin biopsies of the upper and lower right arm. Histopathological examination revealed typical cornoid lamella confirming the diagnosis of porokeratosis. The diagnosis of linear porokeratosis was made. Due to distressing cosmetic problems we started treatment with topical isotretinoin $0.1 \%$ cream once daily and skin care containing $5 \%$ urea.

Six years later the patient presented with new skin lesions affecting both lower legs. Physical examination showed multiple, disseminated reddish-brown annular lesions with prominent hyperkeratotic ridges. These skin eruptions were smaller and less conspicuous than those of the right arm (fig. 1b). The histological examination demonstrated a porokeratosis, so that the clinical diagnosis of disseminated superficial actinic porokeratosis (DSAP) was confirmed. Parents and siblings were not affected. Only a minimal response was noted after 8 -week treatment with imiquimod $5 \%$ cream.

\section{Discussion}

Porokeratosis is a group of genetic disorders characterized by a clonal proliferation of keratinocytes. Up to date, 6 different types have been identified. These include besides classic porokeratosis of Mibelli (PM), disseminated superficial actinic porokeratosis (DSAP), 'linear porokeratosis' ('LP'), porokeratosis palmaris et plantaris disseminata (PPPD), disseminated superficial porokeratosis (DSP) and porokeratosis palmaris et plantaris punctata (PPPP). A distinctive histologic feature of all porokeratotic variants is the cornoid lamella which is characterized by a column of parakeratotic cells extending through the surrounding orthokeratotic stratum corneum, a decreased stratum granulosum beneath the parakeratotic column, dyskeratosis in the underlying stratum malpighii and a dermal perivascular lymphocytic infiltrate.

The classic porokeratosis of Mibelli has a strong family history suggestive of autosomal dominant inheritance and can occur at every age. The multiple reddish-brown lesions with atrophic center mainly develop disseminated on the extremities, less often on the trunk or glans penis. So far, only one case of type 2 segmental porokeratosis of Mibelli was found in the literature [1]. By contrast, DSAP emerges after ultraviolet-exposure and therefore occurs in sun-exposed areas like the back of the hand, the forearms and lower legs and the face. DSAP is an autosomal dominant disorder. Its molecular basis is so far unknown, although three different genetic loci and diverse candidate genes have been proposed $[2,3]$. However, these data could not be reproduced by other groups so far and require further confirmation $[4,5]$. Except for sun exposure, several risk factors have been associated with the development of DSAP, including virus infection, immunosuppression and radioactivity. Linear porokeratosis usually arises in childhood and follows Blaschko's lines.

The coexistence of two different clinical forms of porokeratosis in a single individual is rare. To our knowledge, only 26 cases have been documented in the literature, so far. The most common combination is - as observed in the present patient - a linear porokeratosis combined with a DSAP. Linear porokeratosis is usually the first type of porokeratosis that is apparent in childhood, while DSAP appears later during the fourth and fifth decades of life.

Following the concept by Happle, two types of segmental manifestation of an autosomal dominant skin disease can be distinguished. Type 1 reflects heterozygositiy for a new postzygotic mutation, as exemplified by a case of unilateral DSAP induced by immunosuppressive therapy of pemphigus vulgaris in a 68-year-old patient [6]. By contrast, type 2 results from loss of the corresponding wild-type allele occurring in a heterozygous embryo and reflects either homozygosity or hemizygosity for the underlying mutation, giving rise to rather pronounced segmental lesions that are superimposed on 
the ordinary nonsegmental phenotype [7-9]. Recently, molecular proof of the theory of type 2 segmental manifestation has been provided in Hailey-Hailey disease [10], Cowden syndrome [11, 12] and Darier disease [13]. However, the concept of a type 2 segmental manifestation of an autosomal dominant skin disorder has been proposed for several other diseases and is awaiting further molecular proof (table 1).

Following Happle's theory, the present case of porokeratosis fulfills the criteria of a type 2 segmental manifestation of an autosomal dominant skin disorder [7]. This concept implies that a patient with DSAP carries a heterozygous germline mutation. Loss of the corresponding wild-type allele due to a somatic crossing-over or deletion may occur at an early developmental stage and give rise to a daughter cell representing a precursor of a clone which grows out in a linear pattern following the lines of Blaschko. This theory explains why the segmental lesions appear earlier in life and are more pronounced than the disseminated ones. The allelic loss may represent an initial stage in the process of carcinogenesis and may be responsible for the malignant potential being highest for the linear lesions [9].

In conclusion, our case highlights the importance of recognizing such uncommon segmental involvement being superimposed on the ordinary nonsegmental lesions. Molecular analysis of such cases may help elucidate the etiology of DSAP and corroborate the theory of type 2 segmental manifestation of this disorder.

Table 1. Segmental type 2 manifestation of autosomal dominant skin diseases

\begin{tabular}{lll}
\hline Skin disease & Molecular proof & Reference \\
\hline Hailey-Hailey disease & Provided & 10 \\
Cowden syndrome & Provided & 11,12 \\
Darier disease & Provided & 13 \\
DSAP & Needs to be confirmed & 1 \\
Neurofibromatosis 1 & Needs to be confirmed & 14 \\
Epidermolytic hyperkeratosis of Brocq & Needs to be confirmed & 15 \\
Cutaneous leiomyomatosis & Needs to be confirmed & 16 \\
Acanthosis nigricans & Needs to be confirmed & 17 \\
\hline
\end{tabular}


Fig. 1. Type 2 segmental manifestation of disseminated superficial actinic porokeratosis: a pronounced linear lesions on the right arm present since birth; $\mathbf{b}$ less prominent disseminated lesions present on both lower legs since the age of 67 years.
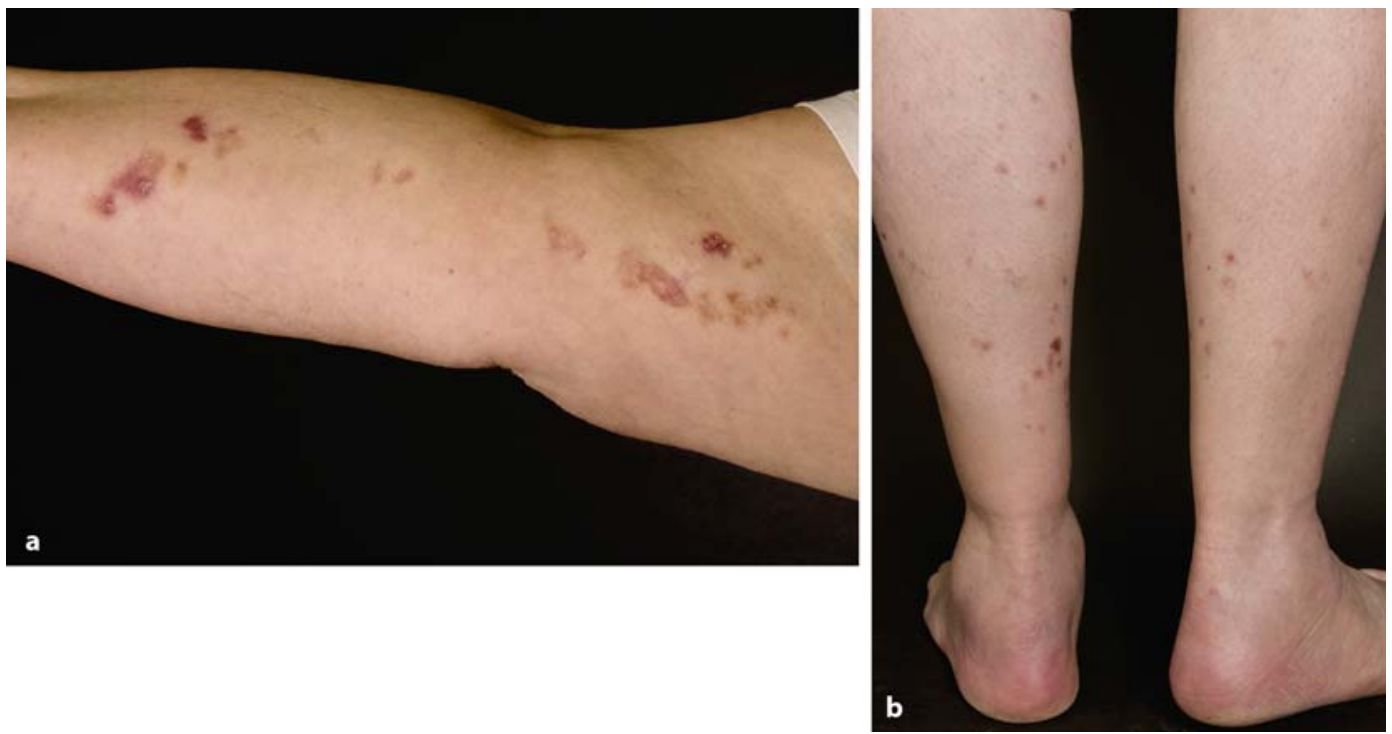


\section{References}

1 Happle R: Mibelli revisited: a case of type 2 segmental porokeratosis from 1893. J Am Acad Dermatol 2010;62:136-138.

2 Liu P, Zhang S, et al: Identification of a genetic locus for autosomal dominant disseminated superficial actinic porokeratosis on chromosome 1p31.3-p31.1. Hum Genet 2008;123:507-513.

-3 Xia JH, Yang YF, Deng H, et al: Identification of a locus for disseminated superficial actinic porokeratosis at chromosome 12q23.2-24.1. J Invest Dermatol 2000;114:1071-1074

-4 Frank J, van Geel M, van Steensel MA: Loss of heterozygosity studies on chromosome $12 \mathrm{q}$ in disseminated superficial actinic porokeratosis: lessons to be learned. J Invest Dermatol 2007;127:2058-2059.

5 Frank J, van Steensel MA, van Geel M: Lack of SSH1 mutations in Dutch patients with disseminated superficial actinic porokeratosis: is there really an association? Hum Mutat 2007;28:1241-1242.

6 Buhl T, Wienrich BG, Sieblist C, Schön MP, Seitz CS: Development of segmental superficial actinic porokeratosis during immunosuppressive therapy for pemphigus vulgaris. Acta Derm Venereol 2010;90:212-213.

-7 Happle R: Segmentale Typ-2-Manifestation autosomal dominanter Hautkrankheiten. Hautarzt 2001;52:283-287.

-8 Happle R: Superimposed segmental manifestation of both rare and common cutaneous disorders: a new paradigm. Actas Dermosifiliogr 2009;100(suppl 1):7785.

-9 Happle R: Cancer proneness of linear porokeratosis may be explained by allelic loss. Dermatology 1997;195:20-25.

10 Poblete-Gutiérrez P, Wiederholt T, König A, Jugert FK, Marquardt Y, Rübben A, Merk HF, Happle R, Frank J: Allelic loss underlies type 2 segmental Hailey-Hailey disease, providing molecular confirmation of a novel genetic concept. J Clin Invest 2004;114:1467-1474.

11 Happle R: Type 2 segmental Cowden disease vs. Proteus syndrome. Br J Dermatol 2007;156:1089-1090.

12 Loffeld A, McLellan NJ, Cole T, et al: Epidermal naevus in Proteus syndrome showing loss of heterozygosity for an inherited PTEN mutation. Br J Dermatol 2006;154:1194-1198.

13 Fölster-Holst R, Nellen R, Jensen JM, Poblete-Gutiérrez P, Schwarz T, Happle R, van Geel M, Frank J: Somatic loss in type 2 segmental manifestation of Darier disease. 15th Meeting of the Working Group on Dermatological Genetics of the Arbeitsgemeinschaft Dermatologische Forschung, Lübeck, 18 February 2010.

14 Yang CC, Happle R, Chao SC, et al: Giant café-au-lait macule in neurofibromatosis 1: a type 2 segmental manifestation of neurofibromatosis 1 ? J Am Acad Dermatol 2007;58:493-497.

15 Akhyani M, Kiavash K, Kamyab K: Bullous ichthyosiform erythroderma in a child born to a parent with systematized linear epidermolytic hyperkeratosis. Int J Dermatol 2009;48:215-217.

16 Renner R, Sticherling M: Familial occurrence of a type 2 segmental manifestation of cutaneous leiomyomatosis. J Dtsch Dermatol Ges 2005;3:695-699.

$\checkmark 17$ Happle R: Type 2 segmental acanthosis nigricans: a historical case explained by a new concept. Arch Dermatol 2008;144:1637. 